\title{
The role of midwife in postpartum hemorrhage
}

\author{
Asimenia Mamakou ${ }^{1}$
}

\section{Dear Editor,}

Globally, about 14 million women will suffer from postpartum hemorrhage. The maternal mortality rate from hemorrhage is up to 1 in 1000 deliveries in developing countries ${ }^{1}$.

In the management of postpartum hemorrhage, midwives have to assess and intervene early or during the hemorrhage, initiating emergency treatment, calling for help, providing help, so the mother regains her strength and complications are prevented.

Of course, the reality is much more complicated. The midwives are called to work effectively in light of their multidisciplinary scientific knowledge and their social, psychological and physiological abilities to ensure a safe surrogate pregnancy and childbirth.

Among the responsibilities of the midwife is the prevention, identification and handling of postpartum hemorrhage. The midwives should make sure that the women breath sufficiently and that they have patent airways. In the event a woman does not respond when the midwife talks to her, a trained individual should immediately handle the situation and ensure no hypoxia will occur, since this could kill her faster than a hypovolemia.

Once all the responsible team members are at the place of birth, they can proceed to the maintenance of the circulatory system and detection of the source of the postpartum hemorrhage. An effective reduction of the morbidity and the mortality due to postpartum hemorrhage can be accomplished by a proper fluid resuscitation ${ }^{2,3}$. Midwives know which fluids are best to be taken and they should make sure that these do not become cold and are administered quickly. Therefore, the lost blood should be replaced until it is variable (3 mL fluid for every $1 \mathrm{~mL}$ lost blood). It is important that the fluid is delivered as fast as possible $e^{2,3}$. The use of a sufficiently wide bore could serve this purpose. Additionally, the women should stay warm, since the hypothermia is a result of a hypovolemic shock ${ }^{2}$. An important step is also the evaluation of the kidney function. In order to control the renal function, an indwelling urinary catheter should be placed following strict aseptic procedures without any infection. Intensive monitoring is necessary ${ }^{4}$. Among the responsibilities of the midwife is the psychological support to the woman and helping the new family member to integrate in its new 'after-delivery' environment ${ }^{4,5}$.

After the birth, women who have not lost their consciousness need to have contact with their child. A skin-to-skin contact is a simple way that can be implemented also on the women who are very ill, with great benefits to them and their child. This technique helps both women and babies to relax ${ }^{6}$ and it has positive effects on the breastfeeding. The traumatic experience of the postpartum hemorrhage results in a longer emotional and physical recovery for the woman.

The work of midwives is essential during a postpartum hemorrhage episode, since they should recognise, prevent and treat the problem. It is important to be trained, to know the risks and to act properly when it is needed. Additional to their scientific knowledge, midwifes should also have soft-skills to provide a wellbeing environment for the women ${ }^{7}$.

\section{REFERENGES}

1. World Health Organisation. WHO Recommendations on Prevention and Treatment of Postpartum Haemorrhage and the WOMAN Trial. https://www.who.int/ reproductivehealth/topics/maternal_perinatal/pph-woman-trial/en/. Published June 15, 2017. Accessed October 8, 2020.

2. Hofmeyr GJ, Mohlala BKF. Hypovolaemic shock. Best Pract Res Clin Obstet Gynaecol. 2001;15(4):645-662. doi:10.1053/beog.2001.0205

3. Clarke J, Butt M. Maternal collapse. Curr Opin Obstet Gynecol. 2005;17(2):157-160.

\section{AFFILIATION}

1 Midwife, Athens, Greece

CORRESPONDENGE TO

Asimenia Mamakou. Midwife, Athens, Greece. E-mail: asimenia.mamakou@gmail. com ORCID ID: https://orcid. org/0000-0002-9824-6812

\section{KEYWORDS}

midwifery care, postpartum hemorrhage, childbirth, vagina bleeding

\section{$\checkmark$}

Received: 27 September 2020 Accepted: 8 October 2020 
doi:10.1097/01.gco.0000162185.53478.34

4. Goebel N. High dependency midwifery care - does it make a difference?. MIDIRS Midwifery Digest. 2004;14:221-226.

5. Simpson KR. Failure to rescue: implications for evaluating quality of care during labor and birth. J Perinat Neonatal Nurs. 2005;19(1):24-34. doi:10.1097/00005237-200501000-00008

6. Carfoot S, Williamson P, Dickson R. A randomised controlled trial in the north of England examining the effects of skinto-skin contact on breast feeding. Midwifery. 2005;21(1):71-79. doi:10.1016/j.midw.2004.09.002

7. Rousseau A, Rozenberg P, Perrodeau E, Deneux-Tharaux C, Ravaud P. Variations in Postpartum Hemorrhage Management among Midwives: A National Vignette-Based Study. PLoS One. 2016;11(4):e0152863. doi:10.1371/journal.pone.0152863

\section{CONFLICTS OF INTEREST}

The author has completed and submitted the ICMJE Form for Disclosure of Potential Conflicts of Interest and none was reported.

\section{FUNDING}

There was no source of funding for this research.

\section{PROVENANCE AND PEER REVIEW}

Not commissioned; internally peer reviewed. 